\title{
Brucellosis Triggering Hemolytic Anemia in Glucose-6-Phosphate Dehydrogenase Deficiency
}

\author{
Gulsum Emel Pamuk ${ }^{\mathrm{a}}$ Aygul Dogan Celik ${ }^{\mathrm{b}}$ Mehmet Sevki Uyanık ${ }^{\mathrm{c}}$

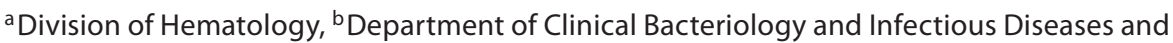 \\ 'Department of Internal Medicine, Trakya University Medical Faculty, Edirne, Turkey
}

\section{Key Words}

Glucose-6-phosphate dehydrogenase deficiency •

Brucellosis - Acute hemolytic anemia

\begin{abstract}
Objectives: To present a case of acute brucellosis triggering acute hemolytic anemia in a subject with glucose-6-phosphate dehydrogenase (G6PD) deficiency. Clinical Presentation and Intervention: A 17-year-old male patient presented with fever, malaise and jaundice. His blood and bone marrow cultures yielded Brucella species. In addition, he was found to have acute hemolytic anemia due to previously undiagnosed G6PD deficiency. He was started on folic acid supplementation and given a combination of doxycycline and rifampicin for 6 weeks. His response to antibiotic therapy was optimal; the hemolytic anemia resolved. There were no further episodes of hemolysis. Conclusion: This case showed that the differential diagnosis of acute hemolytic anemia in subjects with G6PD deficiency should include brucellosis, especially in regions where the infection is endemic.
\end{abstract}

\section{Introduction}

Brucellosis is a zoonotic infection caused by small, fastidious Gram-negative coccobacilli of the genus Brucella [1]. It has a worldwide distribution and is endemic in the Mediterranean basin and some developing countries [2]. Humans may be infected through the ingestion of raw milk, cheese, and insufficiently cooked or raw meat. The disease might also be acquired through direct contact with infected animals, products of conception, or animal excreta $[1,2]$.

Brucellosis may involve any organ system, but the most common complication is osteoarticular involvement. It might also involve hepatosplenomegaly, the nervous system, the genitourinary system, the skin, or the respiratory system [3]. In addition, brucellosis might have various hematological manifestations such as anemia, leukopenia, lymphomonocytosis and, rarely, thrombocytopenia, pancytopenia, and thrombotic microangiopathy [3-6]. The causes of pancytopenia and anemia in brucellosis might be hemophagocytosis, hypersplenism, bone marrow granulomas, bone marrow hypoplasia, immune destruction, and infiltration with malignant diseases $[3,5,6]$.

Glucose-6-phosphate dehydrogenase (G6PD) deficiency is the most common red blood cell enzyme deficiency worldwide. It may lead to acute hemolytic anemia

Dr. Gulsum Emel Pamuk

Eski Yıldız Cad. Park Apt. No:24 Daire:18 Besiktas-Istanbul (Turkey)

Tel. +90 284235 0001, Fax +902842357475

E-Mail gepamuk@yahoo.com 
triggered by infection, the ingestion of certain drugs or broad beans (favism) [7]. Until recently, acute hemolytic anemia triggered by acute brucellosis in G6PD deficiency has not been reported. Herein, we describe a patient with acute brucellosis and G6PD deficiency concurrently that resulted in acute hemolytic anemia.

\section{Case Report}

A 17-year-old male was hospitalized in our Clinical Bacteriology and Infectious Diseases Clinic in November 2005 with the complaints of malaise, fever of 2 weeks' duration, sweating, low back pain, headache, jaundice, and darkening of urinary color of 1 week's duration. He had been living in a village in the Edirne Province in the northwest of Turkey. The patient was a shepherd and his family herded sheep. He admitted consuming raw dairy products and having direct contact with the animals. His past medical history was not contributory: he denied the intake of any drugs, any infectious diseases or favism. His family history revealed cholecystectomy and splenectomy in 2 of his maternal uncles in the third decades of their lives. His initial vital signs were as follows: temperature $39.2^{\circ} \mathrm{C}$; blood pressure $110 / 60 \mathrm{~mm} \mathrm{Hg}$; heart rate $132 / \mathrm{min}$, and respiratory rate $32 / \mathrm{min}$. On physical examination, conjunctivae were pale, sclerae were subicteric, and the skin appeared yellow. Cervical and axillary lymph nodes were $2 \mathrm{~cm}$ in their greatest diameter and splenomegaly and hepatomegaly were evident ( 9 and $4 \mathrm{~cm}$ below the respective costal margin). There was a grade II/VI systolic murmur in the mitral and pulmonary areas; examination of the respiratory system was normal. Neurologic system evaluation revealed no pathology. Whole blood count showed hemoglobin $8.2 \mathrm{~g} / \mathrm{dl}$, hematocrit $23.1 \%$, mean corpuscular volume $84.8 \mathrm{fl}$, leukocytes $4,200 / \mathrm{mm}^{3}$, and platelets $208,000 / \mathrm{mm}^{3}$. The peripheral blood smear revealed polychromasia and nucleated red blood cells, but no schistocytes. The leukocyte differential was composed of 3\% myelocytes, $3 \%$ metamyelocytes, $4 \%$ stabs, $38 \%$ neutrophils, $2 \%$ basophils, $48 \%$ lymphocytes, and $2 \%$ monocytes. On biochemical analysis, total bilirubin was $3.1 \mathrm{mg} / \mathrm{dl}$ (normal $<2.0 \mathrm{mg} / \mathrm{dl}$ ), indirect bilirubin $2.4 \mathrm{mg} / \mathrm{dl}$ (nor$\mathrm{mal}<1.5 \mathrm{mg} / \mathrm{dl}$ ), and lactate dehydrogenase $440 \mathrm{U} / \mathrm{l}$ (normal $<192$ $\mathrm{U} / \mathrm{l}$ ). Other biochemical values including urea, creatinine, electrolytes, ALT, AST, ALP, GGT were normal. Erythrocyte sedimentation rate was $55 \mathrm{~mm} / \mathrm{h}$ and $\mathrm{C}$-reactive protein $5.5 \mathrm{mg} / \mathrm{dl}$ (normal: $0-0.8 \mathrm{mg} / \mathrm{dl}$ ). Bone marrow aspiration was hypercellular with erythroid hyperplasia (myeloid:erythroid ratio 43:41) and toxic granulation of the myeloid cells. The corrected reticulocyte count was $5.8 \%$ and serum haptoglobin level was low $(<5.83 \mathrm{mg} / \mathrm{dl})$. There was increased urinary urobilinogen, but no hemosiderinuria. Direct and indirect Coombs tests were negative; serum vitamin $B_{12}$ and folic acid levels were normal. The value of G6PD was $3.8 \mathrm{IU} / \mathrm{g}$ hemoglobin (normal: 4.6-13.5 IU/g hemoglobin). Any forms of Plasmodium spp. were not seen on the peripheral blood smear prepared on three separate occasions when the patient had high fever. Serologic tests for HBsAg, antiHBs IgG, antiHBc, antiHCV, antiHIV, antiCMV IgM and IgG, antitoxoplasma IgM and IgG, and the monospot and Grubal-Widal tests were negative. Serum slide agglutination (Rose-Bengal) test was positive, and the standard tube agglutination (Wright) test for Brucella spp. was positive at a titer of $1 / 20,480$ on the 4 th day of admission. The antigens in these tests (obtained from Pendik Veterinary Research Laboratory, İstanbul, Turkey) were prepared from B. abortus S-99 strain. Brucella species were isolated from both blood and bone marrow cultures on the 9th day of admission. The species of Brucella could not be identified because further identification tests for Brucella strain could not be performed.

The patient was diagnosed with acute hemolytic anemia due to G6PD deficiency triggered by acute brucellosis. Thorax computed tomography (CT) revealed only axillary lymph nodes $2 \mathrm{~cm}$ in maximal diameter. Abdominopelvic CT showed hepatomegaly $(19 \mathrm{~cm})$ and splenomegaly $(20 \mathrm{~cm})$. Electrocardiography and cranial CT were normal. Radiographic studies of the spine and sacroiliac joints showed no pathology. The patient was started on folic acid after the initial laboratory tests indicated nonimmune hemolysis. He was put on doxycycline $200 \mathrm{mg} /$ day and rifampicin $600 \mathrm{mg} /$ day after the positive tube agglutination test. His fever continued during the first 5 days of antibiotic therapy. After 1 week of antibiotic therapy, his hemoglobin level was $6.5 \mathrm{~g} / \mathrm{dl}$, hematocrit $19.4 \%$, leukocytes $3,300 / \mathrm{mm}^{3}$, platelets $118,000 / \mathrm{mm}^{3}$, corrected reticulocytes $11.5 \%$, lactate dehydrogenase $1,565 \mathrm{U} / 1$. He was transfused with 2 units of red blood cell suspensions. Thereafter, his whole blood count parameters began to improve and his hemolysis stopped. He was discharged after 2 weeks of antibiotic therapy and completed therapy with doxycycline and rifampicin for 6 weeks. On his last follow-up in May 2008, nearly 2.5 years after his initial presentation, he was well, with no complaints and complications; he had a normal whole blood count with no hemolysis and normal biochemical tests. The patient's two follow-up G6PD levels were lower than his initial value.

\section{Discussion}

Brucellosis is a multisystemic infectious disease with a worldwide distribution [1]. Patients with active brucellosis might have various hematological manifestations such as anemia, leukopenia, and relative lymphomonocytosis $[3,4]$. Less frequently, there might be thrombocytopenia, pancytopenia, and hemolysis $[5,6,8]$.

Anemia and pancytopenia in brucellosis might be explained by different mechanisms. One of the causes is hemophagocytosis $[6,9]$. In one large series including 202 patients, more than half of the bone marrow aspirations and biopsies showed histiocytic hyperplasia with prominent phagocytosis of erythrocytes, leukocytes, platelets, and their precursors [6]. Another cause is bone marrow granulomas which have no caseation necrosis [9]. Hypersplenism might be a contributory factor for cytopenias. However, the spleen is usually not huge and cytopenias improve before resolution of splenomegaly, and therefore it seems to play a minor role [6]. Bone marrow hypoplasia is a rarely reported cause for cytopenias. Infiltration of the bone marrow with solid or hematological malignancies might also result in cytopenias in brucellosis patients 
[6]. Immune mechanisms have been suggested to be responsible in some cases $[5,10]$.

One rare cause for anemia in brucellosis is hemolysis, generally in the form of microangiopathic hemolytic anemia [11]. Another case of a patient presenting with acute brucellosis with Coombs-positive autoimmune hemolytic anemia has been reported recently [5]. There has been no report of acute brucellosis triggering acute hemolysis in a patient with G6PD deficiency. Our patient had a positive family history of congenital hemolytic anemia revealing splenectomy and cholecystectomy in 2 of his maternal uncles after transient episodes of jaundice. Nevertheless, he denied any previous attack of hemolysis. He was diagnosed with G6PD deficiency on his initial presentation with acute brucellosis.

G6PD deficiency is present in over 400 million people worldwide, making it the most common enzyme defect in humans. G6PD is the key enzyme of the pentose phosphate pathway, whose principal role is to provide reducing power in the form of NADPH required to counterbalance the oxidative stress triggered by several oxidant agents and preserve the reduced form of glutathione [12]. Although most affected individuals are asymptomatic, it might cause neonatal jaundice, chronic nonspherocytic hemolytic anemia, or acute hemolytic anemia triggered by infection, ingestion of drugs and broad beans [7] Many bacterial, viral and rickettsial infections have been reported as precipitants of acute hemolysis in G6PD de- ficiency, and infectious hepatitis, pneumonia, typhoid fever are particularly important [7]. In this case, Brucella infection might have caused stress to the pentose phosphate pathway resulting in oxidative stress. As a result, G6PD-deficient red blood cells might have hemolyzed.

Acute hemolysis in G6PD deficiency might lead to pallor, palpitations, dyspnea, and even congestive heart failure [5]. Our patient's hemolysis worsened on the initial days of antibrucellosis therapy, and we transfused him with 2 units of red blood cell suspensions because of his tachycardia and tachypnea. Although he only had anemia at initial presentation, he progressively developed pancytopenia. He was given folic acid supplementation and in the days following, therapy with doxycycline and rifampicin. Thereafter, his hemolysis stopped and cytopenias improved.

\section{Conclusion}

We presented this case report to show that acute brucellosis might trigger an acute hemolytic attack in a patient with underlying G6PD deficiency. Such patients' vital signs should be followed up carefully and transfusion undertaken if necessary. This is important especially in countries such as Turkey, where brucellosis is endemic, and there is a high frequency of G6PD deficiency in the population.

\section{References}

1 Namiduru M, Gungor K, Dikensoy O, Baydar I, Ekinci E, Karaoglan I, Bekir NA: Epidemiological, clinical and laboratory features of brucellosis: a prospective evaluation of 120 adult patients. Int J Clin Pract 2003;57: 20-24.

-2 Pappas G, Akritidis N, Bosilkovski M, Tsianos E: Brucellosis. N Engl J Med 2005;352: 2325-2336.

-3 Demiroğlu YZ, Turunç T, Alişkan H, Çolakoğlu S, Arslan H: Brucellosis: retrospective evaluation of the clinical, laboratory and epidemiological features of 151 cases (in Turkish). Mikrobiyol Bul 2007;41:517-527.

-4 Crosby E, Llosa L, Miro Quesada M, Carrillo C, Gotuzzo E: Hematologic changes in brucellosis. J Infect Dis 1984;150:419-424.
5 Sari I, Kocyigit I, Altuntas F, Kaynar L, Eser B: An unusual case of acute brucellosis presenting with Coombs-positive autoimmune hemolytic anemia. Intern Med 2008;47: 1043-1045.

-6 Sari I, Altuntas F, Hacioglu S, Kocyigit I, Sevinc A, Sacar S, Deniz K, Alp E, Eser B, Yildiz O, Kaynar L, Unal A, Cetin M: A multicenter retrospective study defining the clinical and hematological manifestations of brucellosis and pancytopenia in large series: hematological malignancies, the unusual cause of pancytopenia in patients with brucellosis. Am J Hematol 2008;83:334-339.

7 Mehta A, Mason PJ, Vulliamy TJ: Glucose-6phosphate dehydrogenase deficiency. Bail lieres Best Pract Res Clin Haematol 2000;13: 21-38.

8 Starakis I, Polyzogopoulou E, Siagris D, Mazokopakis E, Gogos CA: Unusual manifestation of brucellosis: liver abscess and pancytopenia caused by Brucella melitensis. Eur J Gastroenterol Hepatol 2008;20:349-352. $\checkmark 9$ Al-Eissa YA, Assuhaimi SA, Al-Fawaz IM, Higgy K, al-Nasser MN, al-Mobaireek KF: Pancytopenia in children with brucellosis: clinical manifestations and bone marrow findings. Acta Haematol 1993;89:132-136.

10 Pappas G, Kitsanou M, Christou L, Tsianos E: Immune thrombocytopenia attributed to brucellosis and other mechanisms of Brucella-induced thrombocytopenia. Am J Hematol 2004; 75:138-141.

-11 Altuntas F, Eser B, Sari I, Yildiz O, Cetin M, Unal A: Severe thrombotic microangiopathy associated with brucellosis: successful treatment with plasmapheresis. Clin Appl Thromb Hemost 2005;11:105-108.

12 Frank JE: Diagnosis and management of G6PD deficiency. Am Fam Physician 2005; 72:1277-1282. 